\title{
Renal Function and Solitary Kidney Disease: Wilms Tumour Survivors versus Patients with Unilateral Renal Agenesis
}

\author{
Joanna Stefanowicz ${ }^{\mathrm{a}}$ Radosław Owczuk $^{\mathrm{b}}$ Bogna Kałużyńska ${ }^{d}$ \\ Ewa Aleksandrowicz ${ }^{c}$ Anna Owczarzakc Elżbieta Adamkiewicz-Drożyńska ${ }^{a}$ \\ Anna Balcerska ${ }^{a}$ \\ Departments of a Paediatrics, Haematology, Oncology and Endocrinology, ${ }^{\mathrm{b}}$ Anaesthesiology and Intensive Therapy \\ and ${ }^{\mathrm{C} C l i n i c a l}$ Nutrition and Laboratory Diagnostics, Medical University of Gdansk, and ${ }^{\mathrm{d}}$ Paediatric Nephrologic \\ Clinic, Children's Hospital, Gdansk, Poland
}

\section{Key Words}

Renal function • Solitary kidney • Wilms tumour survivors •

Unilateral renal agenesis

\begin{abstract}
Aims: To test the hypothesis that Wilms tumour survivors (WTs) experience increased disturbance in renal function, even after prompt treatment, compared to patients with unilateral renal agenesis (URA). Methods: To assess the renal function of 30 WTs and 17 individuals with URA, the estimated glomerular filtration rate (eGFR) was calculated using the Schwartz and Filler formulas as well as the new Schwartz equation for chronic kidney disease. To measure kidney damage, serum levels and urine excretion of $\beta_{2}$-microglobulin (B2M), cystatin C (Cys C), neutrophil gelatinase-associated lipocalin (NGAL) were tested, $\mathrm{N}$-acetyl- $\beta$-glucosaminidase (NAG), and albumin urine excretion and urine sediment were examined. Blood pressure was measured. Results: No differences were found between the groups in terms of eGFR, serum Cys C, B2M and NGAL concentrations. The urine excretion of Cys C, NGAL and NAG was similar in both groups. URA patients had higher B2M excretion than WTs. Arterial
\end{abstract}

hypertension was present in 7/30 (23\%) WTs and 1/17 (6\%) patients with URA. Conclusions: WTs have similar eGFR to individuals with URA and are more likely to have arterial hypertension. The patients with URA have signs of tubular damage. This study demonstrates the need for nephrological monitoring of individuals with a single kidney.

Copyright $\odot 2011$ S. Karger AG, Basel

\section{Introduction}

Unilateral functioning solitary kidney involves the absence of one kidney due to unilateral renal agenesis (URA), unilateral atrophic kid ney or unilateral nephrectomy [1]. Both nephrectomy and congenital solitary kidney create a situation in which a single kidney has to take on an additional burden. In nephrectomy, the adaptation is linked with hypertrophy of renal glomeruli and hyperfiltration. In this case, increased glomerular filtration in the remaining nephrons frequently compensates for the sudden loss of functioning renal tissue. Hyperfiltration can be the reason for the progressive sclerosis of glomerular vessels and, consequently, decreased efficiency of

\section{KARGER}

Fax +41613061234 E-Mail karger@karger.ch www.karger.com
(C) 2011 S. Karger AG, Basel

$1420-4096 / 12 / 0353-0174 \$ 38.00 / 0$

Accessible online at: www.karger.com/kbr
Joanna Stefanowicz, MD, $\mathrm{PhD}$

Department of Paediatrics, Haematology, Oncology and Endocrinology

Medical University of Gdansk

7 Debinki Street, PL-80952 Gdansk (Poland)

Tel. +48 5834928 80, E-Mail jstefanowicz@ gumed.edu.pl 
nephron function [2-5]. According to Daw et al. [6], the largest decrease in the estimated glomerular filtration rate (eGFR) in patients with Wilms tumour (32\%) appears directly after nephrectomy; however, both chemoand radiotherapy influence the filtration function of the kidney. The hypertrophy of a solitary kidney is a wellknown phenomenon associated with post-natal nephrectomies and prenatal loss of the contralateral kidney. Wilms tumour survivors (WTs) demonstrate hypertrophy; however, hypertrophy in these cases results from the enlarged size of nephrons, not their increased number [3].

According to the Brenner theory, the reduced filtration surface area of the kidney resulting from an inherited or acquired deficit of glomeruli impairs the normal adjustment of blood pressure (BP) by pressure natriuresis [3]. Therefore, patients with a solitary kidney reveal an increased risk of proteinuria, arterial hypertension and the progression of chronic kidney disease (CKD) [7-10].

This study aimed to verify the hypothesis that patients who are WTs and who required anticancer treatment have worse renal function than patients with URA.

\section{Patients and Methods}

\section{Patients}

The tests were performed on 47 children and young adults with solitary kidneys and without defects of the urinary tract: 17 patients had URA, and 30 were uninephrectomised WTs. The basic criteria for enrolment included the presence of one kidney without other ureteric and kidney anomalies. The test involved an interview with an emphasis on kidney and urinary tract diseases, a physical examination, BP measurement, and taking blood and urine samples.

\section{Methods}

\section{Assessment of GFR}

GFR was measured indirectly using the original Schwartz and Filler formulas and the new Schwartz equation for children with CKD.

The Schwartz formula is defined as follows: GFR in $\mathrm{ml} /$ $\min / 1.73 \mathrm{~m}^{2}=\mathrm{k} \times$ height of child in $\mathrm{cm} /$ serum creatinine concentration in $\mathrm{mg} / \mathrm{dl}$, where the constant $\mathrm{k}$ was defined using the published literature values of $\mathrm{k}=0.55$ for children aged 2-12 years or adolescent females and $\mathrm{k}=0.7$ for adolescent males [11].

Additionally, the serum concentration of cystatin C (Cys C) was evaluated, and GFR was presented according to the Filler formula: $\log \mathrm{GFR}=1.962+[1.123 \times \log (1 /$ Cys $\mathrm{C})][12]$.

The new Schwartz equation for children with CKD was defined as follows: $\mathrm{eGFR}=39.2 \times$ (height of child in metres/serum creatinine concentration in $\mathrm{mg} / \mathrm{dl})^{0.516} \times(1.8 /$ Cys $\mathrm{C}$ serum concentration $)^{0.294} \times(30 / \mathrm{BUN})^{0.169} \times\left(1.099^{\mathrm{male}} / 1^{\text {female }}\right) \times($ height of child in metres/1.4) ${ }^{0.188}$ [13].
Serum creatinine concentration $(\mathrm{mg} / \mathrm{dl})$ was assessed using the colorimetric-modified Jaffe method. Blood ureic nitrogen concentration $(\mathrm{mg} / \mathrm{dl})$ was assessed using the enzymatic-modified Talke and Schubert method.

The concentration of Cys $\mathrm{C}$ in serum and urine was determined using the nephelometric PENIA method (Dade Behring, Marburg, Germany). The concentration of $\beta_{2}$-microglobulin $(\mathrm{B} 2 \mathrm{M})$ in serum and urine was determined by the immunoturbidimetric method using the Quantia $\beta_{2}$-microglobuline kit from Biokit SA (Barcelona, Spain). The concentration of neutrophil gelatinase-associated lipocalin (NGAL) in blood and urine was determined by an immunoenzymatic method with the NGAL ELISA kit from Bioporto Diagnostics (Gentofte, Denmark) according to the manufacturer's instructions. The concentration of albumin in urine was determined immunologically using the Multigent kit from Abbott Laboratories (Wiesbaden, Germany). The activity of $\mathrm{N}$-acetyl- $\beta$-glucosaminidase (NAG) was measured by a colorimetric method as proposed by Maruhn [14], with modifications.

The parameters measured in urine are presented as concentrations and as the product of a given concentration and the concentration of creatinine. The following were adapted as cut-off values: $20 \mathrm{mg} / \mathrm{dl}$ for the concentration of albumins in a portion of urine, $30 \mathrm{mg} / \mathrm{g}$ for the albumin to creatinine ratio [15], $0.32 \mathrm{mg} / \mathrm{dl}$ for the concentration of $\mathrm{B} 2 \mathrm{M}, 0.04 \mathrm{~g} / \mathrm{mol}$ for the B2M to creatinine ratio [16], $0.18 \mathrm{mg} / \mathrm{l}$ for the concentration of Cys C, and 11.3 $\mathrm{mg} / \mathrm{mol}$ for the Cys $\mathrm{C}$ to creatinine ratio [17]. The liminal value of NAG activity was taken as $6.0 \mathrm{IU} / \mathrm{g}$ of creatinine [14].

For each of the individuals enrolled in the study, a urine test was evaluated, and urine sediment was analysed. At the time of the evaluation, none of the children had a urinary tract infection, as confirmed by urine samples and an assessment of blood C-reactive protein levels.

Assessment of Blood Pressure

BP was measured in every child in the study by an auscultatory method that involved a standard clinical sphygmomanometer and a stethoscope. This method followed the guidelines established by the Fourth Report on the Diagnosis, Evaluation, and Treatment of High Blood Pressure in Children and Adolescents [18]. BP was measured three times in each patient. Mean values of systolic and diastolic pressure were determined. The results were then compared to reference values matched according to gender, age and height.

\section{Statistical Analysis}

Statistical analysis was performed using Statistica PL software (Statsoft, Tulsa, Okla., USA). The normality of the obtained data was verified with the W Shapiro and Wilk test. Depending on the distribution, data are presented as the means \pm SD or median value (range). Comparisons were performed using Student's t test for non-dependent data or the Mann-Whitney U test. Correlations were calculated using Pearson's or Spearman's test. Values of $\mathrm{p}<0.05$ were considered significant.

\section{Ethics Committee}

This study was approved by the Independent Bioethical Committee of Scientific Researchers at the Medical University of Gdansk. Written informed consent was obtained from the legal guardians of the children. 
Table 1. Patient characteristics (means \pm SD)

\begin{tabular}{lccc}
\hline & $\begin{array}{l}\text { Group WTs } \\
(\mathrm{n}=30)\end{array}$ & $\begin{array}{l}\text { Group URA } \\
(\mathrm{n}=17)\end{array}$ & p value \\
\hline Sex (female/male) & $10 / 20$ & $9 / 8$ & 0.188 \\
Age, years & $12.8 \pm 5.4$ & $10.2 \pm 5.8$ & 0.129 \\
Height, cm & $152.3 \pm 21.3$ & $140.4 \pm 34.5$ & 0.148 \\
Weight, kg & $43.6 \pm 16.8$ & $42.3 \pm 24.4$ & 0.839 \\
BMI & $17.9 \pm 2.2$ & $19.3 \pm 3.4$ & 0.140 \\
\hline
\end{tabular}

Table 2. eGFR values $\left(\mathrm{ml} / \mathrm{min} / 1.73 \mathrm{~m}^{2}\right)$ assessed using various methods (mean $\pm \mathrm{SD}$ )

\begin{tabular}{llll}
\hline & $\begin{array}{l}\text { Group WTs } \\
(\mathrm{n}=30)\end{array}$ & $\begin{array}{l}\text { Group URA } \\
(\mathrm{n}=17)\end{array}$ & $\begin{array}{l}\mathrm{p} \\
\text { value }\end{array}$ \\
\hline $\begin{array}{l}\text { Schwartz } \\
\begin{array}{l}\text { Filler } \\
\text { New Schwartz equation } \\
\text { for children with CKD }\end{array}\end{array}$ & $121.7 \pm 20.3$ & $126.0 \pm 24.4$ & 0.517 \\
\hline
\end{tabular}

Table 3. LMWP in serum [mean \pm SD or median (range)]

\begin{tabular}{lccc}
\hline & $\begin{array}{l}\text { Group WTs } \\
(\mathrm{n}=30)\end{array}$ & $\begin{array}{l}\text { Group URA } \\
(\mathrm{n}=17)\end{array}$ & $\begin{array}{l}\mathrm{p} \\
\text { value }\end{array}$ \\
\hline Cys C, mg/l & $0.76 \pm 0.13$ & $0.75 \pm 0.13$ & 0.804 \\
B2M, mg/l & $1.94 \pm 0.32$ & $1.83 \pm 0.44$ & 0.327 \\
NGAL, $\mu$ g/l & $192.15 \pm 135.99$ & $137.27 \pm 124.55$ & 0.271 \\
CRP, $\mathrm{mg} / \mathrm{l}$ & $0.44(0.10-10.52)$ & $0.56(0.10-18.20)$ & 0.706
\end{tabular}

$\mathrm{CRP}=\mathrm{C}$-reactive protein.

\section{Results}

\section{Patient Characteristics}

The research involved 30 unilateral WTs and 17 children and young adults with URA. WTs were treated in accordance with the therapeutic protocols SIOP 9, SIOP 9301 and SIOP 2001 between 1987 and 2008, which involved unilateral nephrectomy and chemotherapy or chemo- and radiotherapy with an average age at diagnosis of $3.4 \pm 2.3$ years (range $0.1-8.2$ ). Twenty-three individuals received non-nephrotoxic chemotherapy (vincristine, actinomycin D and doxorubicin). Seven patients were treated with cytostatics, which are proven nephro- toxic agents (e.g. carboplatin and iphosphamide/cyclophosphamide). Three patients received radiotherapy to the entire abdomen area, two of whom also received nephrotoxic chemotherapy.

The tested groups did not differ significantly with regard to sex, age, height, weight or BMI (table 1). There were no significant differences $(\mathrm{p}=0.677)$ in the followup times of WTs (mean \pm SD $9.1 \pm 5.3$ years, median 10.2 , range $0.3-20.5)$ or the ages of the URA patients (10.2 \pm 5.8 years, 10.2 and $1.2-18.6$ ).

\section{Glomerular Filtration Rate}

The eGFR was assessed using three methods. The results are presented in table 2 . The lowest eGFR value was achieved by estimating the GFR using the new Schwartz formula for children with CKD. The eGFR values did not differ between groups.

\section{Low-Molecular-Weight Proteins in Blood Serum}

The average concentration of Cys $\mathrm{C}$ in blood serum was $0.76 \pm 0.13 \mathrm{mg} / \mathrm{l}$ in the WTs group and $0.75 \pm 0.13$ $\mathrm{mg} / \mathrm{l}$ in the URA group. The mean values of remaining low-molecular-weight proteins (LMWP) are presented in table 3. No differences were observed between the groups.

The relationship among Cys $\mathrm{C}, \mathrm{B} 2 \mathrm{M}$ and NGAL as well as that between LMWP and eGFR were assessed using the new Schwartz formula for CKD children. The WTs group showed a strong correlation between eGFR, which was assessed using the new Schwartz formula for CKD and B2M $(r=-0.57, \mathrm{p}<0.05)$ and between B2M and Cys $C$ in serum $(r=0.6, p<0.05)$. The URA group revealed a strong correlation between eGFR (as assessed using the new Schwartz formula) and Cys C ( $\mathrm{r}=-0.55$, $\mathrm{p}<0.05)$ and B2M $(\mathrm{r}=-0.73, \mathrm{p}<0.05)$ as well as between Cys $\mathrm{C}$ and B2M $(\mathrm{r}=0.57, \mathrm{p}<0.05)$. We determined no correlation beween NGAL and eGFR (as assessed in accordance with the new Schwartz formula) nor between NGAL and CysC nor between NGAL and B2M.

\section{Signs of Kidney Damage}

The ratios of the median concentration of the albumins, LMWP and NAG excreted in a sample of urine to excreted creatinine are presented in table 4 . No statistically significant differences were determined between the tested groups with regard to the excretion of the albumins, Cys C, NGAL and NAG. It has been proven that the groups differ with regard to $\mathrm{B} 2 \mathrm{M}$ excretion, which is higher in the URA patients (median $0.18 \mathrm{mg} / \mathrm{g}$ of creatinine, range 0.06-1.53). 
Table 4. Excretion of albumin, Cys C, B2M, NGAL and NAG in urine [median (range)]

\begin{tabular}{lccc}
\hline & $\begin{array}{l}\text { Group WTs } \\
(\mathrm{n}=30)\end{array}$ & $\begin{array}{c}\text { Group URA } \\
(\mathrm{n}=17)\end{array}$ & p value \\
\hline Albumin, mg/l & $9.5(1.8-106.31)$ & $10.4(5.1-91.2)$ & 0.512 \\
Albumin to creatinine ratio, mg/g & $13.5(2.7-112.3)$ & $11.2(3.7-59.7)$ & 0.650 \\
Cys C, mg/l & $0.04(0.01-0.19)$ & $0.06(0.00-0.21)$ & 0.236 \\
Cys C to creatinine ratio, mg/g & $0.04(0.02-0.32)$ & $0.06(0-0.12)$ & 0.508 \\
B2M, mg/l & $0.06(0.01-7.8)$ & $0.14(0.03-1.4)$ & 0.013 \\
B2M to creatinine ratio, mg/g & $0.09(0.01-13.36)$ & $0.18(0.06-1.53)$ & 0.047 \\
NGAL, $\mu$ g/l & $6.44(0.73-78.54)$ & $20.55(0.74-98.41)$ & 0.776 \\
NGAL to creatinine ratio, $\mu \mathrm{g} / \mathrm{g}$ & $13.5(2.06-228.18)$ & $14.53(0.94-196.2)$ & 0.776 \\
NAG, IU/l & $2.7(0.3-10.5)$ & $3.5(0.9-55.2)$ & 0.530 \\
NAG to creatinine ratio, IU/g & $4.7(0.9-33)$ & $3.6(0.5-10.4)$ & 0.480 \\
\hline
\end{tabular}

Table 5. Characteristics of the individuals who received potentially nephrotoxic agents (patients 1 and 3-8) and underwent radiation of a solitary kidney (patients 2, 6, 7)

\begin{tabular}{|c|c|c|c|c|c|c|c|c|}
\hline Patient & 1 & 2 & 3 & 4 & 5 & 6 & 7 & 8 \\
\hline Age, years & 7.1 & 11.4 & 12.7 & 2.3 & 17.9 & 20.3 & 19.5 & 0.9 \\
\hline Age at time of diagnosis, years & 4 & 7.5 & 7.4 & 2.3 & 6.2 & 4 & 2.3 & 0.9 \\
\hline Chemotherapy & yes & no & yes & yes & yes & yes & yes & yes \\
\hline Radiotherapy & no & $\begin{array}{l}\text { total } \\
\text { abdomen }\end{array}$ & no & $\begin{array}{l}\text { yes: bed of } \\
\text { removed } \\
\text { kidney }\end{array}$ & $\begin{array}{l}\text { yes: bed of } \\
\text { removed } \\
\text { kidney }\end{array}$ & $\begin{array}{l}\text { total } \\
\text { abdomen }\end{array}$ & $\begin{array}{l}\text { total } \\
\text { abdomen }\end{array}$ & $\begin{array}{l}\text { yes: bed of } \\
\text { removed } \\
\text { kidney }\end{array}$ \\
\hline Time of follow-up, years & 3.4 & 3.9 & 5.3 & 9 & 11.8 & 15.4 & 16 & 20.6 \\
\hline Hypertension arterialis & no & no & yes & yes & no & no & no & yes \\
\hline eGFR Schwartz, $\mathrm{ml} / \mathrm{min} / 1.73 \mathrm{~m}^{2}$ & 115 & 178 & 113 & 103 & 141 & 95 & 116 & 83 \\
\hline $\begin{array}{l}\text { eGFR new equation for children } \\
\text { with } \mathrm{CKD}, \mathrm{ml} / \mathrm{min} / 1.73 \mathrm{~m}^{2}\end{array}$ & 89.7 & 119.9 & 96 & 94 & 100.3 & 69.3 & 103.1 & 73.8 \\
\hline eGFR Filler, $\mathrm{ml} / \mathrm{min} / 1.73 \mathrm{~m}^{2}$ & 96 & 119 & 133 & 129 & 141 & 90 & 137 & 157 \\
\hline C-reactive protein, mg/l & 7.75 & 0.71 & 1.43 & 0.49 & 3.58 & 0.77 & 0.15 & 10.52 \\
\hline$\underline{\text { Serum Cys C, mg/l }}$ & 0.96 & 0.79 & 0.72 & 0.76 & 0.68 & 1.02 & 0.7 & 0.62 \\
\hline Serum B2M, mg/l & 2.6 & 1.7 & 2.2 & 2.3 & 1.8 & 2.1 & 1.5 & 1.9 \\
\hline$\underline{\text { Serum NGAL, } \mu g / l}$ & 334.45 & 143.63 & 192.15 & 173.71 & 259.6 & 205.2 & 181.86 & 260.34 \\
\hline ACR, mg/g & 35.3 & 17.1 & 69.5 & 43.6 & 15.9 & 10.7 & 7.1 & 5.1 \\
\hline BCR, mg/g & 0.09 & 0.08 & 13.36 & 4.01 & 0.12 & 0.54 & 0.09 & 0.65 \\
\hline CCR, mg/g & 0.08 & 0.04 & 0.33 & 0.30 & 0.05 & 0.05 & 0.04 & 0.02 \\
\hline NGAL to creatinine ratio, $\mu \mathrm{g} / \mathrm{g}$ & 10.58 & 13.72 & 13.5 & 94.91 & 41.96 & 228.18 & 36.78 & 69.43 \\
\hline NAG to creatinine ratio, IU/g & 2.4 & 7.6 & 4.7 & 19.2 & 3.9 & 7.9 & 6.1 & 3.1 \\
\hline
\end{tabular}

$\mathrm{ACR}=$ Urine albumin to creatinine ratio; $\mathrm{BCR}=\beta_{2}$-microglobulin to creatinine ratio; $\mathrm{CCR}=\mathrm{Cys} \mathrm{C}$ to creatinine ratio.

\section{Renal Function of WTs, Potentially Nephrotoxic}

Chemotherapy and Follow-Up Period

The characteristics of individuals who received potentially nephrotoxic agents and underwent irradiation of a solitary kidney are presented in table 5. WT patients with
B2M to creatinine ratio $>0.04 \mathrm{~g} / \mathrm{mol}(0.354 \mathrm{mg} / \mathrm{g})$ received nephrotoxic chemotherapy (table 5). Three of them were irradiated, but in only 1 case on the total abdomen. We analysed the follow-up period of WTs, and the patients were divided into two subgroups. One was com- 
posed of 8 patients who had a follow-up period of $<5$ years, and the second included 22 patients who had a follow-up period of $>5$ years. The numbers of patients in these groups are too few for statistical analyses. Compared to the WTs group with a follow-up of $>5$ years, we recognised more frequent glomerular injury in the WTs group with a follow-up $<5$ years. The GFR estimated by the new equation for children with CKD was $<90 \mathrm{ml} /$ $\mathrm{min} / 1.73 \mathrm{~m}^{2}$ ( 50 vs. $23 \%$ ), serum Cys C $>0.95 \mathrm{mg} / \mathrm{l}$ ( 25 vs. $9 \%$ ) and excretion of NAG to creatinine $>6 \mathrm{IU} / \mathrm{g}$ ( 38 vs. $32 \%)$, but more rarely albumin to creatinine ratio (12.5 vs. $27 \%), \mathrm{B} 2 \mathrm{M}$ to creatinine ratio (0 vs. $18 \%$ ) and Cys C to creatinine ratio (0 vs. $9 \%$ ).

\section{Blood Pressure}

The average diastolic/systolic BP in WTs was verified using three independent tests: 4 children (13\%) demonstrated an average diastolic/systolic BP $\geq 95$ th percentile, 1 child demonstrated 95 th percentile diastolic pressure, and 2 children demonstrated 95th percentile systolic pressure. An average diastolic and/or systolic pressure $\geq 90$ th percentile was observed in 2 patients. One patient had diastolic pressure $\geq 90$ th percentile.

The URA group had systolic pressure $\geq 95$ th percentile in 1 child, at the 90-95th percentile in 3 children, and $<90$ th percentile in 11 children. BP could not be taken in 2 children for technical reasons (the children were crying uncontrollably). In this group, diastolic pressure was $<90$ th percentile in all patients.

\section{Patients with Abnormal Values of Particular \\ Parameters}

The numbers of patients who demonstrated abnormal parameters in tests are presented in table 6.

\section{Discussion}

Our results suggest that glomerular filtration in WTs does not differ from that in URA patients, but the followup time of this study for patients may not have be long enough to detect significant differences in many of the parameters measured. Thus, we can conclude that WTs with unilateral nephrectomy have the same renal function when analysed by indirect GFR as URA patients. Remarkably, URA patients exhibited more B2M urine excretion, the sign of proximal tubule damage, than WTs. WTs have more frequent arterial hypertension than URA patients. However, it should be remembered that both WTs and URA patients have only one kidney, which pre-
Table 6. Number of patients with pathological results

\begin{tabular}{lll}
\hline & $\begin{array}{l}\text { Group WTs } \\
(\mathrm{n}=30)\end{array}$ & $\begin{array}{l}\text { Group URA } \\
(\mathrm{n}=17)\end{array}$ \\
\hline $\begin{array}{l}\text { eGFR Schwartz }<90 \mathrm{ml} / \mathrm{min} / 1.73 \mathrm{~m}^{2} \\
\text { eGFR new equation for children }\end{array}$ & $1(3)$ & 0 \\
$\quad$ with CKD, $<90 \mathrm{ml} / \mathrm{min} / 1.73 \mathrm{~m}^{2}$ & $9(30)$ & $5(29)$ \\
eGFR Filler $<90 \mathrm{ml} / \mathrm{min} / 1.73 \mathrm{~m}^{2}$ & 0 & $1(6)$ \\
Serum Cys C $>0.95 \mathrm{mg} / \mathrm{l}$ & $4(13)$ & $1(6)$ \\
Albumin $>20 \mathrm{mg} / \mathrm{l}$ & $6(20)$ & $3(18)$ \\
ACR $>30 \mathrm{mg} / \mathrm{g}$ & $7(23)$ & $4(24)$ \\
Urine Cys C $>0.18 \mathrm{mg} / \mathrm{l}$ & $1(3)$ & $1(6)$ \\
CCR $>11.3 \mathrm{mg} / \mathrm{mol}$ & $2(7)$ & $1(6)$ \\
Urine B2M $>0.32 \mathrm{mg} / \mathrm{l}$ & $3(10)$ & $4(24)$ \\
BCR $>0.04 \mathrm{~g} / \mathrm{mol}$ & $4(13)$ & $3(18)$ \\
Urine NAG $>6$ IU $/ 1$ & $3(10)$ & 0 \\
NAG to creatinine ratio $>6 \mathrm{IU} / \mathrm{g}$ & $9(30)$ & $3(18)$ \\
\hline
\end{tabular}

Figures in parentheses are percentages. $\mathrm{CCR}=\mathrm{Cys} \mathrm{C}$ to creatinine ratio; $\mathrm{BCR}=\mathrm{B} 2 \mathrm{M}$ to creatinine ratio.

disposes them to CKD. It is necessary to continue research to monitor the development of CKD in both groups of patients.

Individuals with a solitary kidney are a specific group of patients who are predisposed to CKD [19]; this group includes WTs. These patients are particularly at risk of CKD progression due to exposure to additional risk factors, such as chemo- and radiotherapy [20-22]. According to the data collected by two large prospective trials, the 'Italian Registry of Chronic Renal Failure (ItalKid)' and the 'North American Pediatric Renal Trials and Collaborative Studies' (NAPRTCS), Wilms tumour is the cause of 0.3 and $0.5 \%$ of cases of CKD among children and young adults under 21 years of age, respectively [23, 24].

There are different reasons for renal impairment in WTs - tumour invasion, nephrectomy, anticancer treatment and other factors such as hypotension, severe infections and nephrotoxic drugs [20, 21]. Daw et al. [6] maintain that the largest drop in eGFR, 32\%, is observed directly after nephrectomy. Chemotherapy consisted of proven nephrotoxic agents, such as carboplatin and iphosphamide and/or cyclophosphamide, which are applied against Wilms tumour with poor prognosis and can cause kidney malfunction $[6,25,26]$. Two cycles of ICE chemotherapy (iphosphamide, carboplatin, and etoposide) reduce GFR by $7 \%$, but a subsequent series of chemotherapy does not reduce GFR [6]. Cytostatics, such as vincristine and actinomycin $\mathrm{D}$, which are widely used in 
the treatment of this cancer, do not cause kidney damage. Additionally, radiotherapy can negatively impact kidneys. de Graff et al. [27] observed a lower value of the GFR in WTs who underwent radiation of their abdomen compared to patients who did not undergo radiation.

To determine the influence of factors other than nephrectomy on kidney function in WTs, a suitable control group is needed. After consideration of pathophysiological features, this group should include people of the same age who lost a kidney through accident or injury. Those uninephrectomised for an acquired condition would have been an ideal control group; however, there are few such patients. Therefore, we decided to create a control group of children and young adults with URA. The way in which patients with inborn solitary kidney can adapt to the effort required to sustain homeostasis had not been explained. It is now known that there is an eightfold range in normal variation in the number of glomeruli in humans with 2 kidneys, ranging from 200,000 to 1.8 million $[19,28]$. However, it is very interesting to know how many nephrons have one congenital solitary kidney. This topic is controversial [29]. Additionally, the question as to whether such patients develop hyperfiltration has not been answered definitively.

In WTs, the overgrowth of a solitary kidney and the related hyperfiltration result from the increased size of nephrons and the related increase in load, but not from the increased number of nephrons. The enlarged size of nephrons is caused by adaptive changes [3]. Children with URA are typically patients with solitary kidneys, and provided that they do not have any other defects or diseases of the urinary system, these patients may have normal and stable parameters of kidney function for many years [8]. However, the long-term outcome of unhealthy URA adult patients remains potentially poor [ 7 , $30,31]$.

Our study sought to verify the hypothesis that WTs with a solitary kidney more frequently present renal function impairment due to their treatment compared to patients with URA. The comparison was based on eGFR, some parameters of tubule damage and an assessment of BP.

The values of eGFR in both groups were comparable. The author's own research on the appearance of CKD in WTs indicates that half of the examined patients displayed symptoms of kidney damage [22]. Based on analysis of the results presented previously, we may conclude that in WTs, Schwartz's new formula for CKD allows a better GFR estimation than the classical Schwartz and Filler formulas [22].

Renal Function in WTs and URA
The comparison of renal functions (inulin clearance, albuminuria and BP assessment) in URA adults and after complete nephrectomy in childhood due to hydronephrosis presented in the paper by Wikstad et al. [32] confirms our own observations that after many years, both groups of patients still do not demonstrate statistically significant differences with regard to the parameters investigated.

Schreuder et al. [33] assessed the influence of the inborn reduction in kidney mass on renal function and BP in 66 patients; he observed that in patients with solitary kidneys, the average eGFR, as determined by the Schwartz equation, was $93 \pm 20 \mathrm{ml} / \mathrm{min} / 1.73 \mathrm{~m}^{2}$, while arterial hypertension and microalbuminuria appeared in 50 and $25 \%$ of tested patients, respectively.

Cys $\mathrm{C}$ can be a more sensitive marker to aid in the early diagnosis of kidney dysfunction; however, it is not recommended by the NKF as a tool for the assessment of renal function [34]. Our current research found that serum Cys $\mathrm{C}$ concentrations $>0.95 \mathrm{mg} / \mathrm{l}$, which is commonly proposed the cut-off point value for impaired glomerular filtration [35], appeared in 1/17 (6\%) URA patients and $4 / 30(13 \%)$ WTs.

Albuminuria exceeding $20 \mathrm{mg} / \mathrm{dl}$, was noted in $3 / 17$ (18\%) URA patients and 6/30 (20\%) WTs. Arguesco et al. [7] tested the health prognosis in 157 adult URA patients with normal contralateral kidneys. They identified proteinuria $>159 \mathrm{mg} / 24 \mathrm{~h}$ in $19 \%$ of 37 examined patients [7]. Wikstad et al. [32] noted albuminuria in $47 \%$ of patients with solitary kidneys (assessed together with URA and after nephrectomy) and demonstrated that albuminuria increased with the time of observation. Schreuder et al. [33] indicated that $50 \%$ of patients with a congenital reduction of kidney mass exhibited arterial hypertension, displayed microalbuminuria or received anti-hypertension medicines; microalbuminuria was noted in only $23 \%$ of children.

The reduction in kidney mass is linked to adaptation mechanisms not only in glomeruli, but also in renal tubules. We did not expect severe tubule damage in WTs and URA patients, and therefore we did not measure serum urine electrolytes and urine osmolality.

Damage to proximal tubules, as manifested by the increased activity of NAG in URA patients or patients who had nephrectomy in childhood, was reported by Tekin et al. [36]. Increased NAG activity was observed in 3/17 (6\%) URA patients and 9/30 (30\%) unilateral nephrectomy patients; however, the activity of this enzyme was comparable in both groups. In our study, URA patients revealed significantly higher excretion of B2M than patients after

Kidney Blood Press Res 2012;35:174-181 
nephrectomy, which permits one to conclude that this group of patients revealed much more severe damage to the proximal tubule.

Numerous papers published in recent years pertain to the assessment of arterial pressure in patients with a solitary kidney $[1,9,10]$. In our research, arterial hypertension was recognised in 7/30 (23\%) WTs and 1/17 (6\%) patients with URA; this fact is clear evidence of more cardio-renal dysfunction in WTs than in URA patients.

The basic limitation of this research was the fact that the compared groups were small and differed in terms of the number of tested patients. Furthermore, we did not examine GFR using gold standard methods; we only es- timated GFR. Some of the WTs had low muscle mass, and hence the eGFR based on serum creatinine is not a true and real GFR.

The next limitation of the study was the follow-up time. We could not completely rule out the possibility of significant renal impairment if the WTs were followed up longer and had GFR measured using standard methods.

\section{Disclosure}

All the authors declare no competing interests.

\section{References}

1 Dursun H, Bayazit AK, Cengiz N, Seydaoglu G, Buyukcelik M, Soran M, Noyan A, Anarat A: Ambulatory blood pressure monitoring and renal functions in children with a solitary kidney. Pediatr Nephrol 2007;22:559564.

-2 Zucchelli P, Cagnoli L, Casanova S, Donini U, Pasquali S: Focal glomerulosclerosis in patients with unilateral nephrectomy. Kidney Int 1983;24:649-655.

3 Brenner B, Mackenzie H: Nephrons mass as a risk factor for the progression of renal disease. Kidney Int 1997;52:124-127.

-4 Thorner P, Arbus G, Celermajer D, Baumal R: Focal segmental glomerulosclerosis and progressive renal failure associated with a unilateral kidney. Pediatrics 1984;73:806810.

5 Fotino S: The solitary kidney: a model of chronic hyperfiltration in humans. Am J Kidney Dis 1989;13:88-98.

-6 Daw NC, Gregornik D, Rodman J, Marina N, Wu J, Kun LE, Jenkins JJ, McPherson V, Wilimas J, Jones DP: Renal function after ifosfamide, carboplatin and etoposide (ICE) chemotherapy, nephrectomy and radiotherapy in children with Wilms tumor. Eur J Cancer 2009;45:99-106.

-7 Arguesco LR, Ritchey ML, Boyle ET Jr, Milliner DR, Bergstralh EJ, Kramer SA: Prognosis of patients with unilateral agenesis. Pediatr Nephrol 1992;6:412-416.

$\$ 8$ Hegde S, Coulthard M: Renal agenesis and unilateral nephrectomy: what are the risks of living with a single kidney? Pediatr Nephrol 2009;24:439-446.

-9 Seeman T, Patzer L, John U, Dusek J, Vondrak K, Janda J, Misselwitz J: Blood pressure, renal function, and proteinuria in children with unilateral renal agenesis. Kidney Blood Press Res 2006;29:210-215.
10 Mei-Zahav M, Korzets Z, Cohen I, Kessler O, Rathaus V, Wolach B, Pomeranz A: Ambulatory blood pressure monitoring in children with solitary kidney: a comparison between unilateral renal agenesis and uninephrectomy. Blood Press Monit 2001;6:263-267.

11 Schwartz GJ, Brion LP, Spitzer A. The use of plasma creatinine concentration for estimating glomerular filtration rate in infants, children and adolescents. Pediatr Clin North Am 1987;34:571-590.

12 Filler G, Lepage N: Should Schwartz formula for estimation of GFR be replaced by cystatin C formula? Pediatr Nephrol 2003;18:981985.

13 Schwartz GJ, Munoz A, Schneider MF, Mak RH, Kaskel F, Warady BA, Furth SL: New equations to estimate GFR in children with CKD. J Am Soc Nephrol 2009;20:629-637.

14 Maruhn D: Rapid colorimetric assay of $\beta$ galactosidase and $\mathrm{N}$-acetyl- $\beta$-glucosaminidase in human urine. Clin Chim Acta 1976; 73:453-461.

15 Hogg RJ, Portman RJ, Milliner D, Lemley $\mathrm{KV}$, Eddy A, Ingelfinger J: Evaluation and management of proteinuria and nephritic syndrome in children: recommendations from a pediatric nephrology panel established at the National Kidney Foundation conference on proteinuria, albuminuria, risk, assessment, detection, and elimination (PARADE). Pediatrics 2000;105:1242-1249.

16 Guignard JP, Santos F: Laboratory investigations, in Avner ED, Harmon WE, Niaudet P (eds): Pediatric Nephrology. Philadelphia, Lippincott Williams \& Wilkins, 2004, vol 21, pp 399-424.

17 Herget-Rosenthal S, van Wijk JA, BröckerPreuss M, Bökenkamp A: Increased urinary cystatin $\mathrm{C}$ reflects structural and functional renal tubular impairment independent of glomerular filtration rate. Clin Biochem 2007;40:946-951.
18 National High Blood Pressure Education Program Working Group on High Blood Pressure in Children and Adolescents: The fourth report on the diagnosis, evaluation, and treatment of high blood pressure in children and adolescents. Pediatrics 2004;114: 555-576

19 Chevalier RL: When is one kidney not enough? Kidney Int 2009;76:475-477.

20 Paulino AC, Wen BC, Brown CK, Tannous R, Mayr NA, Zhen WK, Weidner GJ, Hussey DH: Late effects in children treated with radiation therapy for Wilms' tumor. Int J Radiat Oncol Biol Phys 2000;46:1239-1246.

-21 Bárdi E, Oláh VA, Bartyik K, Endreffy E, Jenei C, Kappelmayer J, Kiss C: Late effects on renal glomerular and tubular function in childhood cancer survivors. Pediatr Blood Cancer 2004;43:668-673.

22 Stefanowicz J, Kosiak M, Romanowicz G, Owczuk R, Adamkiewicz-Drożyńska E, Balcerska A: Glomerular filtration rate and prevalence of chronic kidney disease in Wilms tumour survivors. Pediatr Nephrol 2011;26:759-766.

23 Ardissino G, Dacco V, Testa S, Bonaudo R, Claris-Appiani A, Taioli E, Marra G, Edefonti A, Sereni F: Epidemiology of chronic renal failure in children: data from the ItalKid project. Pediatrics 2003;111:e382-e387.

24 North American Pediatric Renal Trials and Collaborative Studies: 2008 Annual Report. Rockville, EMMES Corp., 2008. www. emmes.com/study/ped/annlrept/Annual\% 20Report\%20-2008.pdf.

25 Sleijfer DT, Smit EF, Meijer S, Mulder NH, Postmus PE: Acute and cumulative effects of carboplatin on renal function. Br J Cancer 1989;60:116-120.

26 Goren MP, Pratt CB, Viar MJ: Tubular nephrotoxicity during long term ifosfamide and mesna therapy. Cancer Chemother Pharmacol 1989;25:70-72. 
27 de Graaf SS, van Gent H, Reitsma-Bierenes WC, van Luyk WH, Dolsma WV, Postma A: Renal function after unilateral nephrectomy for Wilms' tumour: the influence of radiation therapy. Eur J Cancer 1996;32A:465469.

28 Hughson M, Farris AB III, Douglas-Denton R, Hoy WE, Bertram JF: Glomerular number and size in autopsy kidneys: the relationship to birth weight. Kidney Int 2003;63:21132122.

29 Maluf NS: On the enlargement of the normal congenitally solitary kidney. Br J Urol 1997; 79:836-841.
30 Sanna-Cherchi S, Ravani P, Corbani V, Parodi $S$, Haupt $R$, Piaggio $G$, Degli Innocenti M, Somenzi D, Trivelli A, Caridi G, Izzi C, Scolari F, Mattioli G, Allegri L, Ghiggeri GM: Renal outcome in patients with congenital anomalies of the kidney and urinary tract. Kidney Int 2009;76:528-533.

31 Oldrizzi L, Rugiu C, De Biase V, Maschio G: The solitary kidney: a risky situation for progressive renal damage? Am J Kidney Dis 1991;17(suppl 1):57-61.

32 Wikstad I, Celsi G, Larsoon L, Herin P, Aperia A: Kidney function in adults born with unilateral renal agenesis or nephrectomized in childhood. Pediatr Nephrol 1988;2:177182.

>33 Schreuder MF, Langemeijer ME, Bökenkamp A, Delemarre-Van de Waal HA, Van Wijk AE: Hypertension and microalbuminuria in children with congenital solitary kidneys. J Pediatr Child Health 2008;44:363-368.
34 National Kidney Foundation: NKF KDOQI Guidelines. www.kidney.org/professionals/KDOQI/guidelines_ckd/p5_lab_g4. htm.

35 Fischbach M, Graff V, Terzic J, Bergere V, Oudet M, Hamel G: Impact of age on reference values for serum concentration of cystatin C in children. Pediatr Nephrol 2002;17: 104-106.

36 Tekin N, Kural N, Uslu S: N-acetyl- $\beta$-Dglucosaminidase secretion in patients with unilateral renal agenesis or nephrectomy in childhood. Turk J Pediatr 1996;38:485490.

\section{Erratum}

In the article by Stefanowicz et al. [Kidney Blood Press Res 2012;35:174-181], entitled 'Renal function and solitary kidney disease: Wilms tumour survivors versus patients with unilateral renal agenesis', the following two errors should be corrected: in the first line of the body of table 5 (Age, years), the value for patient 4 should read 12.9 (instead of 2.3) and for patient 8 it should read 23.5 (instead of 0.9). 